\title{
Critical Success Factors for ERP Life Cycle Implementation
}

\author{
Chen Guang-hui ${ }^{1}$, Li Chun-qing ${ }^{1,2}$, and Sai Yun-xiu ${ }^{1}$ \\ 1 School of Management, Xi'an Institute of Technology, Xi' an 710032, \\ P.R.China \\ ghui_chen@163.com,Saiyxiu@263.net \\ 2 School of Economic and Management, Tsinghua University, Beijing, \\ 100084 , P.R.China \\ lichq@em.tsinghua.edu.cn
}

\begin{abstract}
ERP implementations are complex undertakings. The purpose of this study is to establish ERP implementation model in China firms based on project life cycle theory. ERP implementation is an information system project. Drawing from literature research, case research, experts- interview, questionnaire investigation, a critical success factors model is developed that posits that ERP implementation is mostly influenced by top manager support, project champion, external experts, education \& training, accuracy of data, project management factors. The research, divided the project of ERP implementation into programming, executive, stabilization, ascending four phases based on project life cycle, investigates the critical success factors in ERP implementation to provide a better understanding of the key factors leading to implementation success when planning ERP implementation projects and also provides researchers with a foundation for further empirical research.
\end{abstract}

\section{Introduction}

Enterprise resource planning (ERP) systems represent critical organizational resources [1]. ERP provides a total, integrated software solution to manage an organization's core business and information-processing needs. It supports a processoriented view of the business, and increases the efficiency and effectiveness of enterprise-wide business processes [2]. Most firms of any significant size are in some stage of implementing ERP systems. Although ERP systems can bring competitive advantage to organizations, the high failure rate in implementing such systems is a

Please use the following format when citing this chapter: 
major concern [3]. Some of these problems arise from technical aspects of the system, the majority of these problems and failures result from management, social, and organizational issues.

According to the reported, approximately $50 \%$ of the Chinese firms implemented MRPII or ERP is finally failed, the other $30 \%$ to $40 \%$ has not realized the system integration, only then $10 \%$ to $20 \%$ firms succeed in implementation according to budget on time [4].

\section{Literature Review}

The high failure rate of ERP implementation, calls for a better understanding of its critical success factors [5], especially in china. Through an extensive literature review, Nah et al. [6] found 10 articles that provide answers to the question: "What are the key critical factors for ERP implementation success?" These 10 articles were identified through a computer search of databases of published works and conference proceedings in the information systems area. From the review, Nah et al. identified 11 factors as being critical to the successful implementation of ERP systems. These 11 factors are: appropriate business and IT legacy systems; business plan and vision; business process re-engineering (BPR); change management program and culture; communication; ERP teamwork and composition; monitoring and evaluation of performance; project champion; project management; software development, testing, and troubleshooting; and top management support. These factors were obtained after careful analysis and grouping of related sub-factors.

We used these factors identified by Nah et al. [6] and expanded the content of the literature by adding four additional research articles [7 - 10]. In this research, we use this result as a benchmark to evaluate project life cycle's perceptions of critical success factors for ERP implementation.

\section{ERP Implementation Based on Project Life Cycle}

ERP implementation project essentially is a management improvement project, but is not the computer system development project. Thus there is not a proper quantification-tool to measure ERP implementation result. Any an advancement management pattern cannot be pushed freely, and ERP implementation is not exceptional. ERP implementation project has four independent phases according to the project life cycle theory. Each phase's goal, main content, achievement and standard are all difference from another. Therefore it is scientific and effective to enhance the success rate to ERP implementation.

The ERP implementation step is as follows: at first seeking initial business demand, then programming plan, allocating software and implementing software, and at last reengineering business process. 
Ross [11] developed a five-phase model based on 15 case studies of ERP implementation. The phases are design, implementation, stabilization, continuous improvement and transformation. The design phase is essentially a planning phase in which critical guidelines and decisions making for the implementation are determined. Stabilization occurs after cut-over and is a period of time in which system problems are fixed and organizational performance consequently improves. This is followed by a continuous period of steady improvement in which functionality is added. Finally, firms expect to reach the stage of transformation in which organizational boundaries and systems are maximally flexible. Markus and Tanis [12] developed a four-phase model of ERP implementation: chartering, project, shake-down and onwards and upwards. Lynn [13] defined as preparation phase, executive phase, adjustment phase, and ascending phase.

Several points need to be made about these three models. Firstly, Markus \& Tanis [12] and Ross [11] included a planning phase that occurs prior to the actual implementation project. Secondly, these two models collapse the actual implementation project into one discrete unit. Thirdly, these two models include a post-project phase in the model of the whole ERP implementation enterprise. Finally, none of them relates CSFs to the phases of implementation.

The model on which this research is based, the project life cycle, synthesizes previous models in that it recognizes the importance of the planning and postimplementation phases. However, the focus of the model is on the implementation project and the factors that influence a successful outcome at each of the phases of the implementation. The project life cycle model of ERP implementation, shown in Fig. 1, proposes an integrated model in which ERP implementation based on project life cycle is divided by four phases: programming, executive, stabilization, and ascending according to characteristic of information system project and the domestic condition of ERP implementation.

PHASE 1

Fig. 1. The project life cycle model of ERP implementation

\subsection{Programming Phase}

The Programming phase is the start phase of ERP implementation project. Its task is to ready for the next phase. It includes the selection of an ERP, assembly of a steering committee, determination of high-level project scope and broad implementation approach, selection of a project team manager and resource determination. 


\subsection{Executive Phase}

The task in executive phase mainly is to make a business process solution which can satisfy the customers potential demand, and to install system, start implementation project, train the core group, special-subject discuss, medium term and final test. Whether the ERP implementation project will success or failure directly depends on the level of project management in the phase. The phase has five sub-phases: set-up, re-engineering, design, configuration \& testing and installation. Figure 1 provides a graphical representation of project life cycle.

\subsection{Stabilization Phase}

The old system is to be replaced by the new system in the stabilization phase. Also in this phase the data will be transformed and end-user will be trained. The stabilization phase may extend over several years and includes the phases of system repair, extension and transformation, and continued till all end-users can work with the new system proficiency.

\subsection{Ascending Phase}

ERP implementation effect will be compared with the goal that is proposed in the programming sub-phase in order to inspect business process degree, the facility condition and the system execution. It is necessary to detail and correct the system, such as software upgrade.

\section{CSFs for ERP Implementation}

The importance of CSFs differs in each phase. It is displayed that top manager support, project champion, external expert, accuracy and integrity of data, welldefined project goal, project management, educating \& training, methods and tolls implementation, business process reengineering (BPR) and evaluation of performance are all accepted as the top-ten CSFs in Chinese by Ross, Lynn and Sweden IFS Corporation case empirical study [14] and on literature research and expert interview. The results are shown as Table 1. 
Table 1. CSFs for ERP Implementation

\begin{tabular}{ll}
\hline Phases & Factors \\
\hline Programming & $\begin{array}{l}\text { Top manager support, project champion, external expert, project } \\
\text { management, BPR, education \& training, staff cognition }\end{array}$ \\
Executive & $\begin{array}{l}\text { Project champion, project management, external expert, education } \\
\text { \& training, accuracy of data, methods and tolls, BPR, staff }\end{array}$ \\
& cognition, communications \\
Stabilization & $\begin{array}{l}\text { Project champion, education \& training, accuracy of data, methods } \\
\text { and tolls, top manager support, communications }\end{array}$ \\
Ascending & $\begin{array}{l}\text { Project champion, education \& training, evaluation of } \\
\text { performance, top manager support, staff cognition, top manager }\end{array}$ \\
& support \\
\hline
\end{tabular}

\subsection{Project Champion}

The project champion will play very important role in the implementation project. It consists of software supplier and representative of firms. The representative of firms is composed of all of department managers, who will undertake the strong character, and the IT department only gets up to support function, and members of software supplier must be skillful and experience in ERP implementation.

\subsection{Top Manager Support}

ERP implementation is relates to the firm overall management question. Top manager support is the only one CSF that can make ERP implementation successful [15] [16]. The ERP implementation is viewed as a transformation in the way the company does business by top management. Top manager support continuous will ensure enough manpower \& financial \& material to finish the ERP implementation project with the specify quality, quantity and time. Just like Davenport said, it is only top manager that can evaluate and review business \& technique conflict appeared in the ERP implementation process.

\subsection{Education and Training}

Top managers and all system users must be fully educated so they understand how the ERP system should be integrated into the overall company operation. All users must be trained to take full advantage of the system's capabilities. A failure to educate and train all relevant personnel will guarantee implementation problems. Education \& training is carried on grade by grade at all time [17]. Through education $\&$ training, the manager all levels are clear about ERP and the enterprise change after ERP implementation and how to work each post [18]. 


\subsection{Project Management}

The complexity of ERP implementation is very high, given the vast combination of hardware, software and organizational issues involved [19]. One approach to overcoming this kind of complexity is to stress the need for 'a great amount of methodical planning and calculated management' [20]. This approach is often taken in text books on IT project management [21]. However, as organizations and projects evolve over time, so should project management priorities. Some degree of improvisation [22] may also need to be part of the skill set of ERP project managers. Therefore, it is perfected project management strategy that can guarantee ERP implementation success. The ERP project management must have a definitive project plan and an official arrangement [15].

\subsection{Accuracy of Data}

Data entered into an ERP system may be used throughout the organization. Because of the integrated nature of ERP, if inaccurate data is entered into the common database, the erroneous data may have a negative domino effect throughout the enterprise. Inaccurate data can lead to errors in market planning, production planning, material procurement, capacity acquisition, and the like. If a company with inaccurate data just forges ahead under the assumption that data errors will be corrected when they are spotted, the ERP will lose credibility. This encourages people to ignore the new system to continue running the company under the old system [17] [23] [24].

\subsection{External Expert}

The qualified experienced ERP implementation consultant is one of important critical successful factors. Consultant is a go-between among the enterprise and the software supplier, which has the independence objective standpoint and good multidisciplinary knowledge and instruction methodology [25].

\section{Research Method}

Since most ERP implementation research has been done and much has focused on $\mathrm{CSF}$, there is a distinct challenge to develop a research model that adopts the project life cycle from prior research. The CSFs of ERP implementation on project life cycle are shown in Table 1. We will rank these CSFs from empirical in this study. 


\subsection{Questionnaire Designing}

To assess project life cycle' perceptions of the CSF for ERP implementation and the degree to which each factor is considered critical, we developed a survey questionnaire. The questionnaire used in this study attempted to measure its of each CSF illustrated in table 1 in different phase. Most of the items in this study were itemized using Likert-Scale, in which respondents were asked to indicate their level of importance for each of the construct items (CSF) using their response on a fivepoint scale.

\subsection{Data Collection}

A total of 178 responses were received. Each respondent company had implemented ERP system. The questionnaire was sent through internet mail to the 500 organizations and 23 usable surveys were received making the response rate to be around $31 \%$.

\subsection{Data Analysis}

Table 2 presents the results of the survey. From Table 2, we find top manager support influence ERP implementation effect mostly and draw the bar chart as Fig. 2. The top-six CSFs are top manager support, project champion, external expert, education and training, accuracy of data and project management by order. Then we draw a conclusion that CSFs of ERP implementation differ in each phase in Chinese firms, finally develop CSFs model of ERP implementation shown as Fig. 3.

Table 2. Mean rankings of CSFs by degree of importance in ERP implementation

\begin{tabular}{clc}
\hline Order & \multicolumn{1}{c}{ CSF } & Mean \\
\hline 1 & Top manager support & 6.89 \\
2 & Project champion & 6.75 \\
3 & External expert & 6.56 \\
4 & Education \& training & 6.34 \\
5 & Accuracy of data & 6.18 \\
6 & Project management & 6.05 \\
7 & Business process reengineering & 5.84 \\
8 & Communications & 5.62 \\
9 & Staff cognition & 5.45 \\
10 & Methods and tolls & 5.21 \\
11 & Evaluation of performance & 5.03 \\
\hline
\end{tabular}




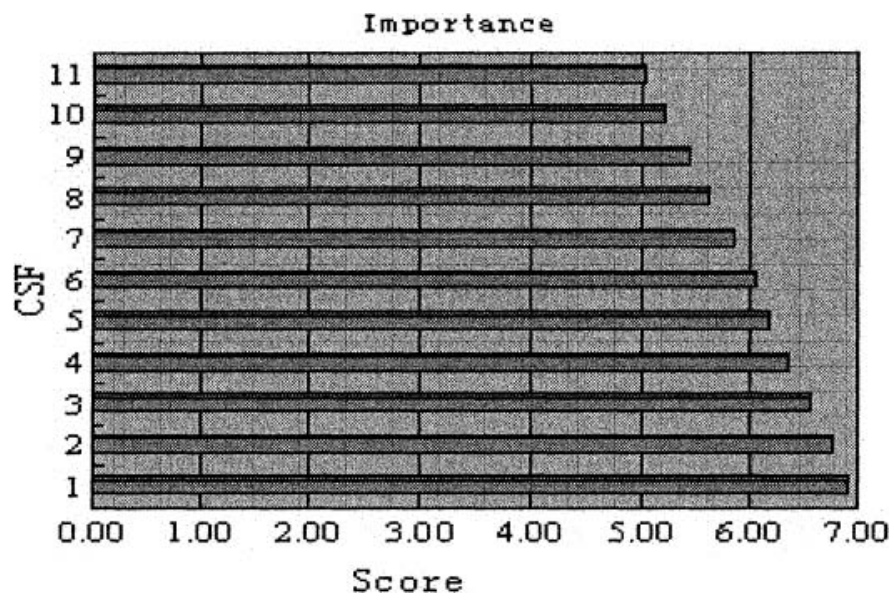

Fig. 2. Rank of CSF

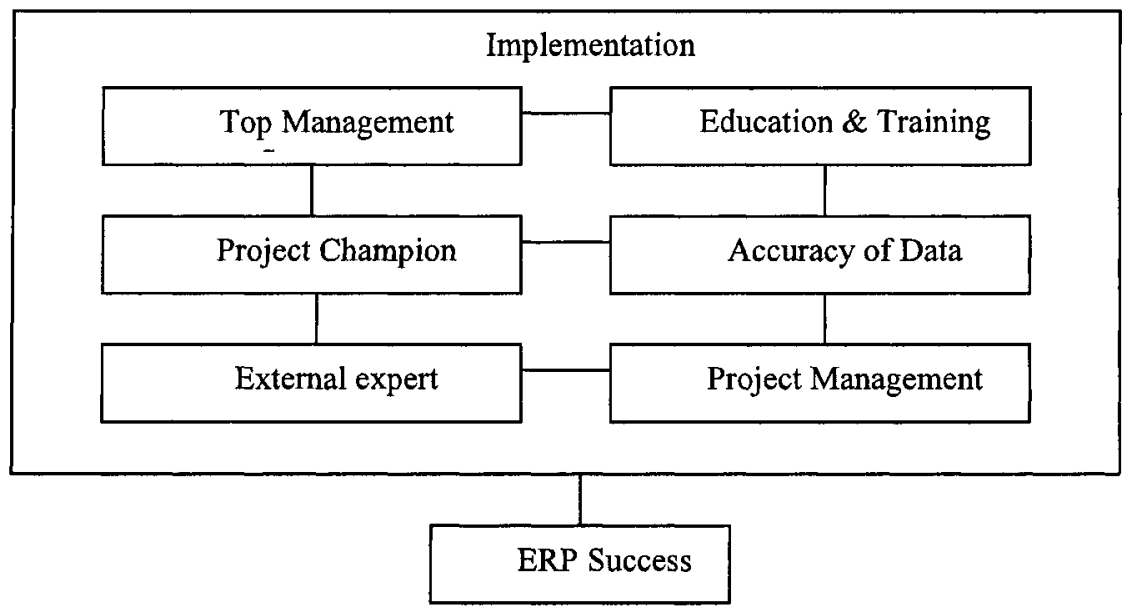

Fig. 3. Critical successful factor model of ERP implementation

\section{Conclusions}

ERP implementations are usually large, complex projects, involving large groups of people and other resources, working together under considerable time pressure and facing many unforeseen developments [26]. This paper has reported on the development of a project life cycle of ERP systems implementation which focuses 
on the implementation project itself and links it to CSFs. That model was used in internet case studies of ERP implementation. Evidence from the case studies suggests that top manager support \& project champion is more important than the other 4 CSFs obviously. For researchers, it is a useful model of ERP system implementation and provides a foundation for further empirical research. For practitioners, it provides a template that suggests important CSFs to consider during particular project phases. The case study findings emphasize that practitioners need to pay even more attention to top manager support of CSFs across the phases of the implementation project.

The research presented in this article has limitations. First, the evidence was gathered only from internet. Second, this article focuses purely on the relationship between implementer and enterprise. In practice, there may be multiple implementation partners or vendors involved, providing different parts of the system or different services.

More focused research efforts will be necessary to validate and develop CSFs of ERP implementation based on project life cycle. We see the findings a starting point to gain a better understanding of how to effectively make sure ERP implementation from failure to success.

\section{Acknowledgement}

This research was supported by National Science Fund from Shaanxi Province (2004G14)

\section{References}

1. K. Dong-Gil, J. K. Laurie, and W.R. King, Antecedents of Knowledge from Transfer from Consultants to Clients in Enterprise System Implementations, MIS Quarterly 3, 59-85 (2005).

2. F.-H. Nah, Introduction, International Journal of Human-Computer Interaction 16(1), 1-3 (2003).

3. T.H. Davenport, Putting the Enterprise into the Enterprise System, Harvard Business Review Jul-Aug, 121-131(1998).

4. K. Reimers, Implementing ERP systems in China, Communications of the AIS 11, 335-356 (2003).

5. T.M. Somers, K. Nelson, and A. Ragowsky, Enterprise Resource Planning (ERP) for the next millennium: Development of an integrative framework and implications for research. Proceedings of the Americas Conference on Information System (Plenum Press, Long Beach, CA, 2000), pp. 998-1004.

6. F.-H. Nah, J. Lau, and J. Kuang, Critical Factors for Successful Implementation of Enterprise Systems, Bussiness Process Management 7, 285-296 (2001).

7. G. Shanks, A. Parr, B. Hu, B. Corbitt, T. Thanasankit, and P. Seddon, Differences In Critical Success Factors In ERP Systems Implementation In Australia And China: Acultural 
Analysis. Proceedings of the 8th European Conference on Information Systems (Plenum Press, Vienna, 2000), pp. 537-544.

8. M. Murray and G. Coffin, A Case Study Analysis of Factors for Success in ERP System Implementations, Proceedings of the Seventh Americas Conference on Information Systems (Plenum Press, Boston, 2001), pp. 1012-1018.

9. F.-H. Nah, K. M. Zuckweiler, and J. L.-S. Lau, ERP Implementation: Chief Information Officers' Perceptions of Critical Success Factors, International Journal of Human-Computer Interaction 16, 5-22 (2003).

10. Parr and G. Shanks, A Model of ERP Project Implementation, Journal of Information Technology 15, 289-303 (2000).

11.J.W. Ross, The ERP Revolution: Surviving Versus Thriving, Centre for Information Systems Research, Sloan School of Management, (1998).

12.M. L. Markus and C. Tanis, The Enterprise Systems Experience - From Adoption to Success, Claremont Graduate University, California, 1999 (unpublished).

13.L.M. Applegate, F.W. McFarllan, and J. L. Mckenney, Corporate Information Systems Management (New York: Mc Graw-Hill.1999).

14. E-Learning, IFS (Sweden, 2003).

15.C. Zhi-xiang, Discussion on Problems of ERP Implementation, China Soft Science 12, 58 61 (2001).

16. Yang Wan-su and Yan Hong-he, The Analysis on Key Factors of Implementing Successful ERP System, Scientific Management Research 1, 46-49 (2001) (in Chinese)

17.E. Umble and M.M. Umble, Avoiding ERP Implementation Failure, Industrial Management 1/2, 25-33(2002).

18. H. Akkermans and K. van Helden, Vicious and Virtuous Cycles in ERP Implementation: A Case Study Of Interrelations Between Critical Success Factors, European Journal of Information Systems 11(1), 35-46 (2002).

19.H.W. Ryan, Managing Development in the Era of Large Complex Systems, Information Systems Management 16, 89-91 (1999).

20.F. Soliman and M.A. Youssef, The Role Of SAP Software In Business Process Reengineering, International Journal of Operations and Production Management, 19, 886895 (1998).

21.J.A. Hoffer, J.F. George, and JS. Valacich, Modern Systems Analysis and Design (2nd ed.), edited by Addison-Wesley, Reading MA (1998).

22.R.D. Macredie and C. Sandom, IT-Enabled Change: Evaluating An Improvisational Perspective, European Journal of Information Systems 8, 247-259 (1999).

23.P.D. Cameron and S.L. Meyer, Rapid ERP Implementation - A Contradiction? Management Accounting 12, 58-60 (1998).

24. J. Beekhuyzen, Organizational Culture and Enterprise Resource Planning (ERP) Systems Implementation, School of Computing and Information Technology, Honours Dissertation, Brisbane, Australia, Griffith University, 2001 (unpublished).

25. J. Hallows, Information Systems Project Management (AMACOM, 1998).

26. H. Akkermans and K. van Helden, Vicious and Virtuous Cycles in ERP Implementation: A Case 37 Study of Interrelations between Critical Success Factors, European Journal of Information Systems 16(3), 418-429 (2002). 